\title{
Desenvolvimento e produtividade do tomateiro sob diferentes freqüências de irrigação em estufa
}

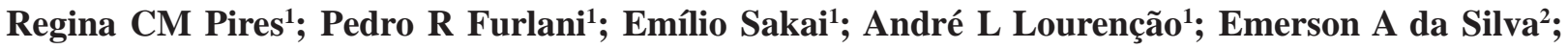 \\ André Torre Neto ${ }^{3}$; Arlete MT Melo ${ }^{1}$ \\ ${ }^{1}$ IAC-APTA, C. Postal 28, 13012-970 Campinas-SP; ${ }^{2}$ Instituto de Botânica, Seção de Fisiologia, C. Postal 3005, 01061-970 São Paulo- \\ SP; ${ }^{3}$ Embrapa Instrumentação Agropecuária, C. Postal 741, 13560-970 São Carlos-SP; rcmpires@iac.sp.gov.br
}

\begin{abstract}
RESUMO
O crescimento de plantas em substrato em cultivo protegido requer conhecimento técnico apropriado para uso racional e eficiente de água e de nutrientes. O objetivo deste trabalho foi avaliar o efeito de seis freqüências de irrigação no desenvolvimento e na produção do tomateiro cultivado em ambiente protegido. O experimento foi conduzido em Campinas, de novembro de 2003 a abril de 2004. O delineamento experimental foi de blocos ao acaso com seis tratamentos e quatro repetições. Os tratamentos consistiram em seis freqüências de irrigação: cinco, quatro, três, duas, uma vez por dia e irrigação em dias alternados. A irrigação foi aplicada por gotejamento. O substrato utilizado foi o composto de fibra de coco. As freqüências de irrigação de uma, três, quatro e cinco vezes por dia resultaram nas maiores produções de frutos comerciáveis de tomateiro. O maior número e peso médio dos frutos foram obtidos nos tratamentos com frequiência de irrigação de uma, duas, três, quatro e cinco vezes por dia. As freqüências de irrigação de uma vez por dia e em dias alternados proporcionaram maior número de frutos não comerciáveis (fundo preto).
\end{abstract}

Palavras-chave: Lycopersicum esculentum Mill., manejo da água, irrigação localizada, fertirrigação, cultivo protegido.

\begin{abstract}
Tomato development and yield under different irrigation frequencies in greenhouse

Plant cultivation in substrate under greenhouse conditions needs technical knowledge to promote water and nutrient use efficiency. In this work were evaluated the tomato development and yield under different irrigation frequencies cultivated in greenhouse. The experiment was carried out in Campinas, São Paulo State, Brazil, from November, 2003 to April, 2004. The experimental design consisted of six treatments in randomized blocks with four replications. The treatments consisted of the irrigation frequencies: five, four, three, two and one times a day and irrigation on alternating days. The irrigation was applied by drip irrigation system. The substrate consisted of coconut fiber. The one, three, four and five times a day irrigation frequency provided better total marketable tomato yield. The greater number of fruits and average weight of fruit were obtained under the one, two, three, four and five times a day irrigation frequencies. The irrigation frequency once a day and alternating days provided greater number of no marketable fruits.
\end{abstract}

Keywords: Lycopersicum esculentum Mill., water management, drip irrigation, fertigation, protected cultivation.

\section{(Recebido para publicação em 5 de dezembro de 2007; aceito em 23 de março de 2009) \\ (Received in December 5, 2007; accepted in March 23, 2009)}

$\mathrm{O}$ cultivo de hortaliças em ambiente protegido no Brasil passou a ser amplamente utilizado a partir do fim dos anos 80 e principalmente no início dos anos 90 (Goto \& Tivelli, 1998). Devido ao cultivo intensivo do solo em estufas, fatores antes pouco relevantes na agricultura convencional, sobressaíram-se, levando a insucessos associados à salinização do solo e problemas relacionados à fitossanidade (Vida et al., 1998). Nos países onde o cultivo protegido encontra-se avançado, o solo vem sendo substituído por substratos. Além destes fatores, ressalta-se também aspectos positivos relacionados à preservação ambiental.

Fontes \& Silva (2002) destacaram alguns aspectos positivos relacionados ao cultivo do tomateiro em estufas e em substrato, com destaque para redu- ção de orvalho nas plantas, diminuição da competição com plantas infestantes e uso de substratos com condições físico-hídricas favoráveis ao desenvolvimento do sistema radicular. Andriolo et al. (1999), citam também a possibilidade de manejo hídrico e nutricional mais apropriado, redução do risco de salinização do meio radicular e de problemas relacionados à sanidade das plantas.

A adoção da fertirrigação integrada ao cultivo protegido resulta em redução da mão-de-obra, melhor distribuição e localização do fertilizante, ajuste aos diferentes estádios de desenvolvimento da cultura e possibilidade de automação (Fernandes, 2001). Nos países cuja agricultura é avançada, o uso de substrato em cultivo protegido associado à fertirrigação é prática consolidada
(Marouelli et al., 2005). No Brasil, alguns trabalhos vêm sendo desenvolvidos no sentido de comparar o desempenho e adequação de diferentes substratos ao cultivo do tomateiro (Fernandes et al., 2002; Carrijo et al., 2004; Fontes et al., 2004). Considerando a avaliação de diferentes tipos de substratos para cultivo do tomateiro em ambiente protegido Carrijo et al. (2004) relataram que a fibra de coco verde pode ter bom desempenho. A adoção da fibra de coco como substrato proporciona destinação ao subproduto da industrialização do fruto para extração da água de coco. Desta forma, o uso da fibra de coco como insumo na produção agrícola tem importância econômica, social e ambiental, uma vez que este é um material de difícil decomposição e reciclagem (Carrijo et al., 2002 e 2004). 
Alguns trabalhos avaliando o desenvolvimento vegetativo do tomateiro em cultivo protegido foram propostos no sentido de estudar o efeito de doses de nutrientes e de tipos de substratos: húmus proveniente da minhocultura, casca de arroz, substrato comercial (composto por matéria orgânica de origem vegetal e vermiculita expandida (Plantmax Folhosas)), casca de arroz parcialmente carbonizada, fibra de coco verde, lã de rocha, maravalha, serragem e substrato para produção de mudas (contendo terra de subsolo, casca de arroz e esterco de galinha) (Andriolo et al., 1999; Grave et al., 2001; Carrijo et al., 2004). Carrijo et al. (2004) obtiveram maior produtividade da cultura do tomate quando utilizaram fibra de coco como substrato em experimentos em casas de vegetação. Andriolo et al. (2004) avaliaram a produtividade do tomateiro cultivado em substrato com diferentes concentrações de nitrogênio na solução nutritiva em dois ciclos de produção, no outono e na primavera, e observaram que a concentração de $\mathrm{N}$ na solução nutritiva afetou a produtividade da cultura, porém não foi observada resposta similar nos dois ciclos de cultivo. Fontes et al. (2004) realizaram estudo sobre produção e qualidade do tomate cultivado em substrato, no campo e em ambiente protegido e constataram que a maior produção e melhor qualidade ocorreu na estufa. O manejo da irrigação tem importância no sistema de cultivo em ambiente protegido em substrato com reflexos diretos na produtividade. Prados \& Lopez (1998) destacaram a importância de investigações sobre o consumo de água e a frequiência da fertirrigação neste sistema de produção. Dentre os elementos essenciais às plantas do tomateiro relacionados à disponibilidade de água e qualidade do fruto destaca-se o cálcio. Segundo Papadopoulos (1991), na maioria dos casos a deficiência de cálcio na planta é induzida, sendo a principal causa o estresse de água devido à falta ou excesso de água na irrigação.

O objetivo do presente trabalho foi avaliar o efeito de seis freqüências de irrigação no desenvolvimento e na produção do tomateiro cultivado em am- biente protegido sobre substrato de fibra de coco em Campinas.

\section{MATERIAL E MÉTODOS}

O experimento foi conduzido em estufa, de novembro de 2003 a abril de 2004 no IAC, em Campinas-SP. As dimensões da estufa eram de 7 x $50 \mathrm{~m}$, com estrutura em arco, coberta com filme de polietileno transparente de $100 \mu \mathrm{m}$ de espessura, orientada a $245^{\circ} 75^{\prime}$ em relação ao norte magnético, latitude $22^{\circ} 54^{\prime} \mathrm{S}$, longitude $47^{\circ} 05^{\prime}$ 'W e a $669 \mathrm{~m}$ de altitude. Lateralmente, a estufa era protegida com sombrite com tramas para reduzir $30 \%$ da radiação, o que possibilitava o fluxo de ar entre os ambientes interno e externo.

Utilizaram-se mudas do híbrido de tomateiro Sahel, de crescimento indeterminado e frutos tipo saladete (Grupo Santa Cruz). O transplantio ocorreu em 24 e 25 de novembro de 2003 , utilizando como recipiente, vaso de plástico mole, com capacidade de 14 L. Apesar da capacidade de vaso atingir $14 \mathrm{~L}$, optou-se pela utilização de apenas $10 \mathrm{~L}$ de substrato. O substrato utilizado foi a fibra de coco, Golden Mix Granulado, composto a partir de $100 \%$ de fibra de coco, de textura fina, sem adubação de base. $\mathrm{O}$ experimento foi finalizado com a última colheita em 7 de abril de 2004.

$\mathrm{O}$ delineamento experimental foi em blocos ao acaso, com seis tratamentos e quatro repetições, totalizando 24 parcelas, instaladas longitudinalmente ao maior lado da estufa. As dimensões da parcela eram de 7,2 $\mathrm{m}$ de comprimento com duas fileiras de vasos espaçados por $0,80 \mathrm{~m}$ entre as linhas de plantio e de $0,40 \mathrm{~m}$ na linha de plantio, resultando em 36 plantas, ou seja, 18 vasos por fileira com uma planta por vaso, totalizando densidade populacional de 3,125 plantas $\mathrm{m}^{-2}$ conforme as recomendações para cultivo em estufas (Gallegos, 2001). Consideraram-se como plantas úteis para fins de avaliação da produção aquelas situadas nas partes centrais de cada uma das linhas, num total de 20 plantas por parcela e consideradas como bordadura as 16 plantas situadas nas extremidades, nas quais foram efetuadas as medidas destrutivas de fenologia. Os tratamentos implantados foram: irrigação 5 vezes por dia (T1), irrigação 4 vezes por dia (T2), irrigação 3 vezes por dia (T3), irrigação 2 vezes por dia (T4), irrigação 1 vez por dia (T5) e irrigação em dias alternados (T6). As irrigações foram realizadas por gotejamento, com um emissor por planta, no período diurno entre 8 e 16 horas. $\mathrm{O}$ gotejador era do tipo auto compensante e anti-drenante (RLM PC/ NL), com vazão nominal de $3,2 \mathrm{~L} \mathrm{~h}^{-1}$. Os emissores foram instalados na linha de irrigação, com microtubo e estaca para cada vaso. A lâmina de irrigação foi avaliada pelo consumo de água do dia anterior pela diferença no peso observada em lisímetros e pela mensuração do volume de irrigação aplicado e o volume percolado coletado. O lisímetro consistia de um vaso sobre balança com capacidade de até $50 \mathrm{~kg}$ e sensibilidade de $0,01 \mathrm{~kg}$, com estrutura que permitia coletar o percolado para um recipiente. Foram instalados dois lisímetros por tratamento. Na fase inicial do desenvolvimento vegetativo, em função da precisão da balança e devido à pequena variação de massa das plantas optou-se fazer o manejo pela mensuração da diferença entre o volume de solução aplicado na irrigação e coletado no percolado.

No período de pegamento das plantas, as irrigações foram iguais para todos os tratamentos. A diferenciação dos tratamentos ocorreu a partir de 6 de dezembro após o pegamento das plantas, no estádio de desenvolvimento inicial das plantas, 11 dias após o transplantio. Cada irrigação consistiu em uma fertirrigação. A formulação da solução nutritiva adotada na fertirrigação foi segundo recomendação de Sonneveld \& Straver (1994) com adaptações de acordo com observações de deficiências visuais das plantas, análise foliar e da solução percolada. Na Tabela 1 encontramse as formulações das soluções A e B e o procedimento de preparo das soluções usadas na fertirrigação. Em todos os estádios de desenvolvimento a solução concentrada dos tanques A e B foi utilizada na proporção de $12,5 \mathrm{~L}$ por $1000 \mathrm{~L}$ de água. Na fase vegetativa, as concentrações dos macronutrientes $\left(\mathrm{mg} \mathrm{L}^{-1}\right)$ 
Tabela 1. Composições das soluções nutritivas concentradas usadas para o preparo das soluções de fertirrigação (concentrated nutrient solution composition used to prepare fertigation solutions). Campinas, IAC, 2003-2004.

\begin{tabular}{|c|c|c|}
\hline Soluções concentradas & 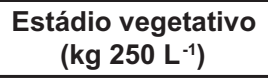 & 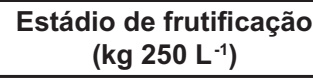 \\
\hline \multicolumn{3}{|l|}{ Solução A } \\
\hline Nitrato de $\mathrm{Ca}$ & 15,0 & 15,0 \\
\hline Sol. Micros 10X, L & 2,0 & 2,0 \\
\hline Quelato de Fe (6\%) & 0,6 & 0,6 \\
\hline Solução B & $\left(\mathrm{kg} 250 \mathrm{~L}^{-1}\right)$ & $\left(\mathrm{kg} 250 \mathrm{~L}^{-1}\right)$ \\
\hline Nitrato de $\mathrm{K}$ & 9,0 & 9,0 \\
\hline MAP & 4,0 & 2,0 \\
\hline MKP & 0 & 3,0 \\
\hline Sulfato de Mg & 8,0 & 8,0 \\
\hline Sulfato de K & 0 & 3,0 \\
\hline Solução de micronutrientes $10 \mathrm{X}$ & $\left(\mathrm{g} 10 \mathrm{~L}^{-1}\right)$ & $\left(g 10 L^{-1}\right)$ \\
\hline Ácido Bórico & 300 & 300 \\
\hline Sulfato de Cobre & 50 & 50 \\
\hline Sulfato de Manganês & 200 & 200 \\
\hline Sulfato de Zinco & 75 & 75 \\
\hline Molibdato de Sódio & 15 & 15 \\
\hline
\end{tabular}

foram de: $\mathrm{N}-\mathrm{NO}_{3}(167), \mathrm{N}-\mathrm{NH}_{4}(30), \mathrm{P}$ (52), K (164), Ca (143), Mg (36) e S (48) enquanto que na fase reprodutiva foram de: $\mathrm{N}_{-} \mathrm{NO}_{3}$ (167), N-NH (19), P (59), K (268), Ca (143), Mg (36) e S (74). Para os micronutrientes, as concentrações foram idênticas nas duas fases conforme segue $\left(\mathrm{mg} \mathrm{L}^{-1}\right)$ : $\mathrm{B}(0,5), \mathrm{Cu}(0,1)$, Fe-EDDHMA $(1,8)$, Mn $(0,4)$, Mo $(0,06)$ e $\mathrm{Zn}(0,2)$. Alem disso, foi adotada como rotina a avaliação da condutividade elétrica da solução de fertirrigação, sempre que preparadas nos tanques, para assegurar valores iguais para todos os tratamentos e de acordo com o previsto no cálculo da solução nutritiva. $\mathrm{O}$ pH da solução nutritiva foi medido eventualmente. As irrigações eram programadas em painel de controle automático nas quais a injeção de nutrientes era precedida pela homogeneização da solução através da agitação mecânica nos tanques de solução. Na solução percolada dos lisímetros, além da quantificação do volume, avaliou-se também a condutividade elétrica. Em media a condutividade elétrica da solução lixiviada ao longo do experimento foi 0,96, 0,92, 1,21, 1,14, 1,02 e 1,19 dS m ${ }^{-1}$ nos tratamentos T1, T2, T3, T4, T5 e T6, respectivamente. Inicialmente a condutividade elétrica (CE) nos tan- ques das soluções dos diferentes tratamentos foi preparada para atingir valor de $2,0 \mathrm{dS} \mathrm{m}^{-1}$ e alterada a composição a partir de 19 de dezembro para proporcionar CE de 1,5 dS m $\mathrm{m}^{-1}$.

No decorrer do ciclo de cultivo foram efetuados os tratos culturais necessários para adequada condução da cultura, tais como desbrota, tutoramento, limpeza de folhas velhas e de plantas infestantes nos vasos e na estufa e aplicação de produtos fitossanitários. As avaliações foram conduzidas com uma haste por planta sendo o tutoramento efetuado na posição vertical com fitilho (Marin et al., 2005). Dentre as pragas que exigiram controle-fitossanitário e sobre as quais foram realizadas diversas aplicações de defensivos químicos destacam-se: mosca-branca, grilo, lagarta-rosca, ácaros, traça-do-tomateiro, tripes e moscaminadora. Os produtos utilizados foram: thiamethoxam, imidacloprid, clothianidin, acetamiprid, piriproxifen, buprofezin, cartap, carbaril, avermectin, pirazofós, captan e fenarimol. Para os inseticidas, realizou-se rotação de produtos nas aplicações, procurando-se alternar os produtos com mesma forma de ação (neonicotinóides, reguladores crescimento e carbamatos).

De modo a verificar a influência do regime de irrigação no status hídrico das plantas de tomate, foram realizadas ao longo do dia medidas do potencial da água nas folhas $\left(\Psi_{\text {wf }}\right)$ utilizando-se uma bomba de pressão tipo Scholander (PMS Instrument, Model 1000). As medidas foram realizadas nos horários de 05:00, 08:00, 10:00, 13:00, 15:00 e 16:00 horas. Em cada horário de medida, foram consideradas 5 repetições por tratamento. As avaliações foram realizadas aos 107 dias após o transplantio (DAT).

Para avaliação do desenvolvimento vegetativo foram realizadas três amostragens ao longo do ciclo aos 43, 99 e 141 dias após o transplantio (DAT), nos estádios: desenvolvimento vegetativo pleno e início de floração; desenvolvimento vegetativo, floração e maturação; e maturação, respectivamente. Foram avaliadas as alturas e o diâmetro da haste da planta na superfície do substrato, o índice de área foliar (IAF) e a matéria seca da parte aérea (MSPA). Para a amostragem em cada época foram retiradas três plantas por tratamento em parcelas distintas. No laboratório procedeu-se mensuração do diâmetro da haste da planta na superfície do substrato e a medida da altura das plantas, seguidos pela separação das folhas para avaliação da área foliar. A área foliar foi medida utilizando-se integrador de área foliar (LICOR LI-3100). Para determinação da matéria seca da parte aérea (MSPA) o material foi seco em estufa a $70^{\circ} \mathrm{C}$, até peso constante, seguido da pesagem final. Os dados referentes ao desenvolvimento vegetativo foram analisados em cada época de coleta separadamente.

Os frutos foram colhidos duas vezes por semana, à medida que ocorriam mudanças na sua coloração, de 27 de janeiro até 7 de abril de 2004, quando encerrou-se o experimento, totalizando 19 colheitas. Avaliaram-se a produção total, o número de frutos comerciáveis e não comerciáveis, diferenciando estes entre os com fundo preto dos com defeitos (forma e rachadura) e o peso médio dos frutos. Os dados referentes ao desenvolvimento vegetativo e à produção total foram submetidos à análise de variância, pelo 
teste F. As médias foram comparadas pelo teste de Duncan, ao nível de $5 \%$ de probabilidade.

\section{RESULTADOS E DISCUSSÃO}

Observa-se que não houve efeito significativo dos tratamentos em relação ao diâmetro da haste na primeira e segunda época de avaliação (Tabela 2). No entanto, aos 141 DAT observase menor desenvolvimento do diâmetro da haste quando as irrigações ocorreram em dias alternados (T6) quando comparado à irrigação duas vezes ao dia (T4).

Com relação à altura das plantas (Tabela 2) nota-se que aos 43 DAT o valor observado no T3 (irrigação 3 vezes por dia) foi maior e diferiu significativamente do T4. O T3 não diferiu estatisticamente dos demais tratamentos. Na segunda avaliação, notase a redução de altura das plantas no T6 em relação aos tratamentos T2, T3 e T5. Não foram observadas diferenças nas alturas das plantas entre os tratamentos T1, T2, T3, T4 e T5, bem como entre os tratamentos T1, T4 e T6. Na última avaliação, nota-se redução na altura das plantas à medida que se diminuiu o número de irrigações, sendo estatisticamente diferente aquela avaliada nas plantas do T6 quando comparada às dos tratamentos T1, T2 e T3.

Observa-se para o IAF, que aos 43 DAT os tratamentos T1 e T3 diferiram estatisticamente de T4, T5 e T6, sendo os menores valores obtidos em T4 e T6 (Tabela 2). Na segunda época de amostragem, o menor IAF ocorreu nas plantas do T6 (irrigações em dias alternados) diferindo dos avaliados nos tratamentos T1, T2 e T3. Aos 141 DAT, na fase final de cultivo do tomateiro, não foi observada diferença no IAF entre os tratamentos avaliados. Andriolo et al. (1999) encontraram valores de IAF no final do ciclo do tomateiro cultivado em estufa variável de acordo com o substrato utilizado, sendo que os valores obtidos foram maiores que no presente trabalho (Tabela 2). Fayad et al. (2001)

Tabela 2. Valores médios de diâmetro da haste (cm), da altura das plantas (m), do índice de área foliar (IAF) e da matéria seca da parte aérea por planta (MPSA) em diversas frequiência de irrigação do tomateiro, cultivado em substrato em estufa. (mean values of stem diameter $(\mathrm{cm})$, plant height $(\mathrm{m})$, leaf area index (IAF) and dry matter in the above-ground part $(\mathrm{g})$ of tomato plants in various irrigation treatments, grown in coconut fiber substrate under greenhouse conditions). Campinas, IAC, 2003-2004.

\begin{tabular}{|c|c|c|c|c|c|c|}
\hline \multirow{2}{*}{$\begin{array}{l}\text { Freqüência } \\
\text { de } \\
\text { irrigação }\end{array}$} & 43 DAT & 99 DAT & 141 DAT & 43 DAT & 99 DAT & 141 DAT \\
\hline & \multicolumn{3}{|c|}{ Diâmetro da haste $(\mathrm{cm})$} & \multicolumn{3}{|c|}{ Altura das plantas (m) } \\
\hline$\overline{\mathrm{T} 1}$ & $1,37^{*} a$ & $1,57 \mathrm{a}$ & $2,00 a b$ & $1,42 a b$ & $2,59 a b$ & $2,81 \mathrm{a}$ \\
\hline T2 & $1,21 \mathrm{a}$ & $1,65 a$ & $2,01 a b$ & $1,42 a b$ & $2,93 \mathrm{a}$ & $2,86 \mathrm{a}$ \\
\hline T3 & $1,38 \mathrm{a}$ & $1,74 \mathrm{a}$ & $2,04 a b$ & $1,43 \mathrm{a}$ & $3,02 \mathrm{a}$ & 2,93 a \\
\hline T4 & $1,38 a$ & $1,57 \mathrm{a}$ & $2,19 a$ & $1,32 b$ & $2,70 a b$ & $2,65 a b$ \\
\hline T5 & $1,30 \mathrm{a}$ & $1,78 \mathrm{a}$ & $1,72 a b$ & $1,37 a b$ & $2,87 \mathrm{a}$ & $2,65 a b$ \\
\hline T6 & $1,38 \mathrm{a}$ & $1,49 a$ & $1,52 b$ & $1,37 \mathrm{ab}$ & $2,34 \quad b$ & $2,41 \quad b$ \\
\hline \multirow[t]{2}{*}{$\mathrm{CV}(\%)$} & 12,6 & 12,8 & 14,4 & 3,7 & 9,0 & 5,5 \\
\hline & \multicolumn{3}{|c|}{ Índice de área foliar } & \multicolumn{3}{|c|}{ Matéria seca parte aérea $(\mathbf{g})$} \\
\hline$\overline{\mathrm{T} 1}$ & $3,55 \mathrm{a}$ & $5,92 \mathrm{a}$ & $2,32 \mathrm{a}$ & $119,8 \mathrm{a}$ & $318,3 \mathrm{a}$ & $245,2 \mathrm{a}$ \\
\hline T2 & $3,15 a b$ & $5,72 \mathrm{a}$ & $2,29 a$ & $107,5 \mathrm{a}$ & 312,8 a & 232,3 a \\
\hline T3 & $3,46 \mathrm{a}$ & $5,78 a$ & $1,90 \mathrm{a}$ & $118,8 \mathrm{a}$ & $288,5 \mathrm{a}$ & $216,5 a b$ \\
\hline $\mathrm{T} 4$ & $2,50 \mathrm{~b}$ & $4,75 a b$ & $1,95 a$ & $90,5 \mathrm{~b}$ & $242,9 \mathrm{a}$ & $162,8 \quad b$ \\
\hline T5 & $2,70 \quad b$ & $4,60 a b$ & $2,18 \mathrm{a}$ & $92,9 \mathrm{~b}$ & $272,6 \mathrm{a}$ & $187,2 \mathrm{ab}$ \\
\hline T6 & $2,57 \quad b$ & $4,13 \mathrm{~b}$ & $1,90 \mathrm{a}$ & $91,9 \mathrm{~b}$ & $228,2 \mathrm{a}$ & $158,9 \quad b$ \\
\hline$\overline{C V(\%)}$ & 12,1 & 15,1 & 16,2 & 6,4 & 17,7 & 16,2 \\
\hline
\end{tabular}

*Médias seguidas pela mesma letra na coluna não diferem entre si pelo teste de Duncan $(\mathrm{p}<0,05)$. (*means followed by the same letter are not different by Duncan test $(\mathrm{p}<0.05))$.

observaram redução do IAF a partir de 90 dias após o transplantio de forma similar ao observado no presente trabalho, comparando a segunda e a terceira época de amostragem. O valor de pico de IAF do tomateiro em estufa encontrado por Fayad et al. (2001) foi de 4,12, inferior àqueles obtidos no T1 a T5 e superior ao T6. Considerando 36 DAT e 105 DAT, Pires et al. (2006) observaram valores de IAF, variando de 1,14 a 1,57 e de 2,39 a 3,66, respectivamente, e, portanto, menores que os obtidos na primeira e na segunda época de avaliação no presente trabalho (Tabela 2). Tal diferença pode ter ocorrido em função da condução dos tratos culturais relacionados à limpeza das folhas baixeiras adotada pelos autores. Em trabalho de reutilização da solução nutritiva drenada com valores elevados de condutividade elétrica no cultivo do tomateiro em substrato em estufa no outono e na primavera em Santa Maria, RS, Andriolo et al. (2003) obtiveram valores de IAF menores, em épocas semelhantes de amostragens (43 e 99 DAT), que os apresentados na Tabela 2. Cabe ressaltar que as condições de cultivo avaliadas pelos autores eram estressantes o que pode ter refletido no desenvolvimento da cultura. Valores de IAF de 6 a 7, e, portanto, acima dos apresentados na Tabela 2 foram obtidos por Rattin et al. (2003), no entanto, com densidade de plantas, cerca de $10 \%$ acima da adotada no presente trabalho.

O fracionamento da irrigação e da fertirrigação favoreceu o incremento da matéria seca da parte aérea (MSPA) das plantas nos tratamentos T1, T2 e T3 quando comparado aos tratamentos $\mathrm{T} 4$, T5 e T6 na primeira época de amostragem (Tabela 2). No entanto, as diferenças não se mantiveram nas avaliações efetuadas aos 99 DAT, provavelmente, devido ao elevado valor de coeficiente de variação (CV) observado, visto que com a pequena redução desse índice na terceira época de amostragem, com diferenças de peso semelhantes de MSPA à segunda avaliação entre tratamentos, novamente diferenças significativas foram observadas. As plantas do T4 e do T6 tiveram menor desenvolvimento em relação aquelas do T1 e T2 diferindo 
Tabela 3. Valores médios por planta de produção total $(\mathrm{kg})$, de número de frutos e de peso médio dos frutos comerciáveis $\left(\mathrm{kg}_{\text {fruto }}{ }^{-1}\right)$, e número médio de frutos não comerciáveis em 20 plantas, com fundo preto e com defeitos (forma e rachaduras) obtidos em seis tratamentos de irrigação ao longo do ciclo do tomateiro, cultivado em substrato em estufa (mean values of total yield per plant $(\mathrm{kg})$, number and mean weight of marketable fruits $\left(\mathrm{kg} \mathrm{fruit}^{-1}\right)$ and mean number of no marketable fruits in 20 plants, with blossom-end rot and tomato fruit desorders (size and fruit cracking) in six irrigation treatments of tomato plants, grown in coconut fiber substrate under greenhouse conditions.*). Campinas, IAC, 2003-2004.

\begin{tabular}{|c|c|c|c|c|c|}
\hline \multirow{2}{*}{$\begin{array}{l}\text { Freqüência } \\
\text { de irrigação }\end{array}$} & \multicolumn{3}{|c|}{ Frutos comerciáveis } & \multicolumn{2}{|c|}{$\begin{array}{c}\text { Frutos não comerciáveis } \\
\text { (20 plantas) }\end{array}$} \\
\hline & $\begin{array}{c}\text { Produção } \\
\left(\text { kg planta- }^{-1}\right)\end{array}$ & $\mathbf{N}^{0}$ planta $^{-1}$ & $\begin{array}{l}\text { Peso médio } \\
\text { (kg fruto }^{-1} \text { ) }\end{array}$ & Fundo preto & Defeitos \\
\hline$\overline{\mathrm{T} 1}$ & 5,75 a & $57,5 a b$ & $0,1040 \mathrm{a}$ & $1,25 \quad b$ & 11,0 a \\
\hline $\mathrm{T} 2$ & 6,00 a & 58,8 a & 0,1049 a & 1,50 & $6,8 \quad a$ \\
\hline T3 & $5,50 \mathrm{ab}$ & $56,5 a b$ & 0,1037 a & 1,25 & 11,0 a \\
\hline $\mathrm{T} 4$ & $5,00 \quad b c$ & $54,5 a b$ & $0,1008 a b$ & 2,75 & 10,3 a \\
\hline T5 & 5,75 a & 59,3 a & $0,1007 a b$ & 6,25 a & $6,8 \quad a$ \\
\hline T6 & 4,50 & $52,8 \quad b$ & $0,0949 \quad b$ & 9,25 a & 7,5 a \\
\hline$\overline{C V}(\%)$ & 7,78 & 5,66 & 4,71 & 58,2 & 38,5 \\
\hline
\end{tabular}

*Médias seguidas pela mesma letra na coluna não diferem entre si pelo teste de Duncan $(\mathrm{p}<0,05) .(*$ means followed by the same letter are not different by Duncan test $(\mathrm{p}<0.05))$.

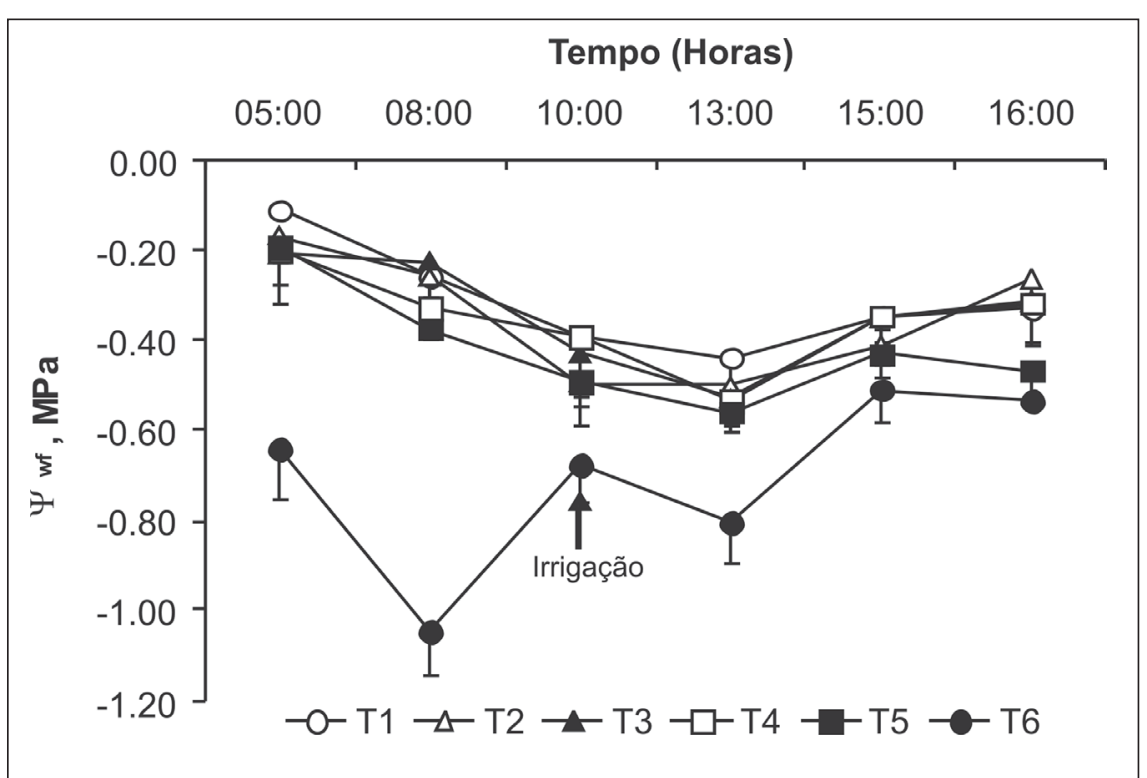

Figura 1. Potencial da água nas folhas $\left(\Psi_{\text {wf }}\right)$ do tomateiro cultivado em seis tratamentos de irrigação, aos 107 dias após o transplantio. (leaf water potential $\left(\Psi_{w f}\right)$, in tomato plants, in six irrigation treatments, 107 days after transplantation). Campinas, IAC, 2003-2004.

estatisticamente das mesmas. Os valores de MSPA, na terceira avaliação, não diferiram estatisticamente entre os tratamentos T1, T2, T3 e T5. Tal diferença também não ocorreu entre os tratamentos T3, T4, T5 e T6. Os valores de MSPA do tomateiro observados nos tratamentos com irrigação mais frequentes (T1) na terceira e na segunda época de amostragem foram semelhantes aos obtidos por Andriolo et al. (1999) e Rattin et al. (2003), respectivamente. Grave $e t$ al. (2001) obtiveram valores acima dos apresentados na Tabela 2 no início do período de maturação dos frutos. Em cultivo do tomateiro em estufa, em Viçosa-MG, Fayad et al. (2001) observaram valores de pico de MSPA acima dos apresentados na Tabela 2. No entanto, aos 99 DAT os valores obtidos nos tratamentos com irrigações mais frequientes (T1 e T2) são semelhantes aos obser- vados por estes autores. Em condição de salinidade elevada observada através da avaliação da condutividade elétrica da solução nutritiva utilizada (variando de 3,3 a 8,9 $\mathrm{dS} \mathrm{m}^{-1}$ nos dois anos de cultivo apresentados) Andriolo et al. (2003) obtiveram valores de MSPA inferiores aos obtidos na primeira e segunda época de amostragem (Tabela 2) no outono e na primavera. Considerando o número de dias após o transplantio semelhante (aos 36 e aos 105 DAT), Pires et al. (2006) observaram valores acima dos obtidos no presente trabalho (Tabela 2). No entanto, ressalta-se que o cultivo ocorreu no outono-inverno, período mais favorável ao desenvolvimento da cultura, com menor demanda evaporativa do ambiente que o do presente trabalho durante a primavera-verão.

As frequiências de irrigação influenciaram significativamente o potencial da água no tomateiro (Figura 1). Os menores valores foram observados no tratamento T6 (-1,06 MPa). O curso diário do potencial da água nas plantas de tomate demonstra que os decréscimos no $\Psi_{\text {wf }}$ coincidem com o horário de maior demanda atmosférica (por volta das 13:00 h) e indicam que a maior freqüência de irrigação favorece a manutenção do status hídrico das plantas no sistema de cultivo protegido, com valores mínimos de $\psi_{\text {wf }}$ variando de - 0,44 a $-0,56 \mathrm{MPa}$ nos tratamentos $\mathrm{T} 1$ e $\mathrm{T} 5$ respectivamente.

Os valores médios de produção de frutos do tomateiro Sahel, obtidos de 27 de janeiro a 7 de abril de 2004 indicam que de um modo geral a irrigação efetuada numa única operação ou fracionando-a em duas a cinco vezes ao longo do dia favoreceu o aumento da produção, tanto em peso quanto em número de frutos, quando comparada à aplicação a cada dois dias (Tabela 3). No entanto, observa-se tendência de diminuição no peso médio dos frutos à medida que diminui o número de operações, com diferenças significativas entre o grupo de tratamentos com irrigação mais freqüente (T1, T2, T3) e a irrigação em dias alternados (T6). Nas plantas do T6 onde foram observados 
os menores valores de produção por planta e peso de frutos (Tabela 3) foram observados os menores valores ($1,06 \mathrm{MPa})$ de potencial de água na folha (Figura 1). Tal fato pode ser relacionado ao maior intervalo entre irrigações adotado no tratamento. Os resultados do desempenho dos tratamentos de frequência de irrigação adotados estão correlacionados ao volume de substrato utilizado bem como às características de retenção de água do mesmo. Em cultivo do tomateiro em substrato em cultivo protegido, Fernandes et al. (2002) verificaram que a fertirrigação aplicada com maior freqüência aumentou a produção de frutos, sendo que esse efeito positivo de irrigações mais freqüentes no cultivo em substratos também foi ressaltado por Marouelli et al. (2005). Estes resultados estão de acordo com a tendência observada no presente estudo (Tabela 3). Os valores de produção de frutos do tomateiro apresentados na Tabela 3 foram maiores que os observados por Fayad et al. (2001), Eklund et al. (2005) no cultivo do tomateiro em solo e por Rattin et al. (2003), Carrijo et al. (2004), Fontes et al. (2004), Carrijo et al. (2002) e Carvalho \& Tessarioli Neto (2005) em condições de cultivo protegido em substrato. Com relação ao número de frutos e ao peso médio dos frutos, Carvalho \& Tessarioli Neto (2005), obtiveram menores valores comparando-se os resultados apresentados na Tabela 3 com população de plantas semelhante, condução de um ramo por planta e o mesmo tipo de fruto do avaliado no presente estudo.

Além dos aspectos quantitativos, fatores qualitativos da produção são fundamentais no cultivo de tomate para consumo in natura. De acordo com os resultados da Tabela 3 , notase que as irrigações menos freqüentes (T5 e T6) desfavoreceram a assimilação de cálcio, uma vez que a movimentação deste elemento do substrato à superfície radicular ocorre através do fluxo de massa, resultando em maior número de frutos com fundo preto em relação aos demais tratamentos. Por outro lado, com relação ao número de frutos com defeito (forma e rachaduras) não houve efeito significativo dos tratamentos, mas menor número de frutos defeituosos foi obtido em T2 e T5 mantendo o mesmo desempenho que os parâmetros produção e número de frutos.

De modo geral as irrigações mais frequientes favoreceram o desenvolvimento vegetativo e produtivo do tomateiro fertirrigado em condições de cultivo protegido em substrato de fibra de coco (Tabelas 2 e 3 ), tanto nos aspectos quantitativos quanto qualitativos. Para as condições em que se realizou o experimento as frequiências de irrigação de uma, três, quatro e cinco vezes por dia favoreceram a produção de frutos por planta (Tabela 3). No entanto, considerando os frutos não comerciáveis (Tabela 3) os tratamentos com freqüência de irrigação de uma vez por dia e em dias alternados resultaram em maior número de frutos com fundo preto.

\section{REFERÊNCIAS}

ANDRIOLO JL; DUARTE TS; LUDKE L; SKREBSKY EC. 1999. Caracterização e avaliação de substratos para o cultivo do tomateiro fora do solo. Horticultura Brasileira 17: 215-219.

ANDRIOLO JL; ROSS TD; WITTER M. 2004. Crescimento, desenvolvimento e produtividade do tomateiro cultivado em substrato com três concentrações de nitrogênio na solução nutritiva. Ciência Rural 34: 1451-1457.

ANDRIOLO JL; WITTER M; ROSS TD; GODÓI RS. 2003. Crescimento e desenvolvimento do tomateiro cultivado em substrato com reutilização da solução nutritiva drenada. Horticultura Brasileira 21: 485-489.

CARRIJO OA; LIZ RS; MAKISHIMA N. 2002. Fibra de casca do coco verde como substrato agrícola. Horticultura Brasileira 20: 533540.

CARRIJO OA; VIDAL MC; REIS NVB; SOUZA RB; MAKISHIMA N. 2004. Produtividade do tomateiro em diferentes substratos e modelos de casas de vegetação. Horticultura Brasileira 22: 5-9.

CARVALHO LA; TESSARIOLI NETO J. 2005. Produtividade de tomate em ambiente protegido, em função do espaçamento e número de ramos por planta. Horticultura Brasileira 23: 986989.
EKLUND CRB; CAETANO LCS; SHIMOYA A; FERREIRA JM; GOMES JMR. 2005. Desempenho de genótipos de tomateiro sob cultivo protegido. Horticultura Brasileira 23: 1015-1017.

FAYAD JA; FONTES PCR; CARDOSO AA; FINGER FL; FERREIRA FA. 2001. Crescimento e produção do tomateiro cultivado sob condições de campo e ambiente protegido. Horticultura Brasileira 19: 365-370.

FERNANDES ALT. 2001. Fertirrigação na cultura do melão em ambiente protegido, utilizando fertilizantes organominerais $e$ químicos. Campinas: UNICAMP-FEAGRI. $94 \mathrm{p}$ (Tese doutorado).

FERNANDES C; ARAÚJO JAC; CORÁ JE. 2002. Impacto de quatro substratos e parcelamento da fertirrigação na produção de tomate sob cultivo protegido. Horticultura Brasileira 20: 559-563.

FONTES PCR; LOURES JL; GALVÃO JCC; CARDOSO AA; MANTOVANI EC. 2004. Produção e qualidade do tomate produzido em substrato, no campo e em ambiente protegido. Horticultura Brasileira 22: 614619.

FONTES PCR; SILVA DJH. 2002. Fatores climáticos. In: FONTES PCR (ed). Produção de tomate de mesa. Viçosa: Editora Aprenda Fácil. p 23-25.

GALLEGOS HML. 2001. Manual para el cultivo de tomate em invernadero. Chihuahua: Gobierno del Estado de Chihuahua. 239p.

GOTO R; TIVELLI SW. 1998. Produção de hortaliças em ambiente protegido: condições subtropicais. São Paulo: Fundação Editora da UNESP. 319p.

GRAVE RA; ANDRIOLO JL; BARTZ HR. 2001. Acumulação de matéria seca do tomateiro cultivado em substrato com diferentes doses de fertilizantes. Ciência Rural 31: 873-875.

MARIN BG; SILVA DJH; GUIMARÃES MA; BELFORT G. 2005. Sistemas de tutoramento e condução do tomateiro visando produção de frutos para consumo 'in natura'. Horticultura Brasileira 23: 951-955.

MAROUELLI WA; CARRIJO OA; ZOLNIER S. 2005. Variabilidade espacial do sistema radicular do tomateiro e implicações no manejo da irrigação em cultivo sem solo com substratos. Horticultura Brasileira 23: 57-60.

PAPADOPOULOS AP. 1991. Growing greenhouse tomatoes in soil and soilless media. Ontário: Agriculture Canada Publication. 79p.

PIRES RCM; FURLANI PR; ROCHA ABO; SAKAI E; LOURENÇÃO AL; TORRE NETO A; MELO AMT; BODINE JUNIOR D. 2006. Desenvolvimento vegetativo do tomateiro cultivado em diferentes volumes de substrato e freqüências de irrigação em estufa. In: CONGRESSO BRASILEIRO DE ENGENHARIA AGRÍCOLA, 35. Anais... João Pessoa: SBEA. 4p. (CD-ROM) 
PRADOS NC; LOPEZ TM. 1998. Programacion del riego. In: CADAHIA C (ed). Fertirrigacion: Cultivos hortícolas y ornamentales. Madrid: Ediciones MundiPrensa. p.265-286.

RATTIN JE; ANDRIOLO JL; WITTER M. 2003. Acumulação de massa seca e rendimento de frutos de tomateiro cultivado em substrato com cinco doses de solução nutritiva. Horticultura Brasileira 21: 2630 .
SONNEVELD C; STRAVER N. 1994. Nutrient solutions for vegetables and flowers grown on water or substrates. The Netherlands, Proefstation voor Tuinbouw onder Glas Te Naaldwijk. 45p. (Series: Voedingsoplossingen Glastuinbouw, 8).

SONNEVELD C. 1995. Fertigation in the Greenhouse Industry. In: PROC. OF THE DAHLIA GREIDINGER INTERNATIONAL SYMPOSIUM ON FERTIGATION, TECHNION. Proceedings... Haifa: Israel Institute of Technology. p121-140.
VIDA JB; KUROZAWA C; ESTRADA KRFS; SANTOS HS. 1998. Manejo fitossanitário em cultivo protegido. In: GOTO R; TIVELli SW (eds.). Produção de hortaliças em ambiente protegido: condições subtropicais. São Paulo: Fundação Editora da UNESP. p.53-104. 